\title{
El factoring: Alternativa financiera para la obTención de LIQUIDEZ EN LAS MICROEMPRESAS
}

\author{
FACTORING: FINANCIAL TOOL FOR THE \\ GAINING OF LIQUIDITY IN MICROENTERPRISES
}

Mg. Juan Doenitz Martínez Guevara
Universidad Tecnológica Israel
jmartinez@uisrael.edu.ec

Fecha de recepción: 15/05/2014

Fecha de aceptación: 13/06/2014

\section{Resumen}

El presente documento aborda el tema de Factoring como herramienta financiera de apoyo a las microempresas para la obtención de recursos monetarios a corto plazo, considerando que éstas son el motor de desarrollo de toda economía. Se ha realizado el análisis de la problemática en torno al crecimiento empresarial de las microempresas en el país, y se estudia la base conceptual sobre Factoring como herramienta versátil, dinámica y poco aplicada en las empresas mencionadas, una vez hecho el estudio nace como recomendación para mejorar el acceso al financiamiento, la promoción de la intermediación financiera no bancaria.

Palabras clave: Factoring, liquidez, microempresas, sistema financiero, facturas. 


\section{Abstract}

This paper addresses the issue of factoring as a financial tool to support microenterprises to obtain short-term monetary resources, considering that these are the engine of growth of any economy. To that effect was made analyzing the issues surrounding business growth of microenterprises in the country and explores the conceptual basis on Factoring as versatile, dynamic and little applied in the companies mentioned, having done the study comes a recommendation to improve access to finance, promote nonbank financial intermediation.

Keywords: Factoring, liquidity, micro-financial system, invoices. 


\section{Introducción}

El desarrollo económico en todo tipo de organización está ligado íntimamente con el campo de las finanzas, puesto que toda actividad económica o corporativa a nivel local, regional o mundial cualquiera sea su actividad o tamaño se la valora en términos monetarios, por lo que se evidencia la importancia que se le debe dar al área financiera en el desarrollo organizacional.

El Ecuador y América Latina tienen como base de desarrollo el aporte de las microempresas, éste sector productivo se ha convertido en el eje central de la economía, puesto que su actividad permite la generación de empleo, dinamiza los procesos de producción y comercialización de productos y/o servicios, por lo que para mantener su operatividad requieren recursos monetarios en la mayoría de los casos en corto plazo, y la falta de acceso a los mismos, así como el desconocimiento de herramientas financieras para generarlos, ha dado origen al cierre de muchas empresas durante sus primeros años de operatividad.

Por lo antes dicho, es necesario abordar el tema del Factoring como herramienta financiera de apoyo al desarrollo y mantenimiento de las microempresas, tomando en consideración que dicha actividad se encuentra respaldada legalmente por la Ley General de Instituciones Financieras que regulan la operación de las entidades financieras que brindan este tipo de servicios, mientras que para las entidades privadas la Superintendencia de Compañías es el órgano rector, mediante el Consejo Nacional de Valores, considerando para el objeto la Ley de Mercado de Valores consagrado en su Art. 1, en el cual se menciona el "promover un mercado organizado, eficaz y transparente, que se logra con información veraz, completa y oportuna; por lo que es necesario formalizar en el mercados de valores una práctica habitual en el medio con la negociación de facturas".

\section{Planteamiento del problema}

La economía nacional se encuentra fortalecida por la alta participación y operatividad de las Micro, Pequeñas y Medianas Empresas - MIPYMES, así lo mencionó en rueda de prensa Ricardo Zambrano, subsecretario de MIPYMES y Artesanías del Ministerio de Industrias y Productividad - MIPRO, al afirmar que: "para el año 2011 el crecimiento de este sector productivo fue del 38\%, mientras que para el 2012 asciende en tres puntos porcentuales al $41 \%$. Se podría decir que el dato registrado, hace referencia a las microempresas que se 
encuentran legalmente registradas y laborando, por tanto este indicador económico es inferior a la realidad nacional, es así que según estudios realizados por el Banco Mundial de Desarrollo "más del 80\% de las micro y pequeñas empresas no son totalmente formales...".

Las causas de la informalidad en las actividades económicas de las micro empresas, se deben a las dificultades de acceso a medios de financiamiento por las condiciones crediticias que exige en la actualidad el Sistema Financiero Nacional, al escaso conocimiento de herramientas financieras para acceder a recursos monetarios, a la falta de información sobre formas de financiamiento directo o inmediato para obtener liquidez, al desconocimiento de procedimientos de administración tributaria, y a los trámites engorrosos que les obliga a invertir tiempo y dinero.

A pesar de las dificultades que enfrenta este sector productivo, éste se encuentra en constante crecimiento y por ende tiene que afrontar la competitividad del mercado, para ello debe recurrir a ingresos monetarios solicitados en el Sistema Financiero, que les permita tener mayor liquidez y recursos monetarios para su operatividad. Como se puede observar los datos proporcionados por la Superintendencia de Compañías revelan cómo a partir del 2002, este tipo de empresas requieren de mayores recursos monetarios para su operatividad como se aprecia en el siguiente gráfico.

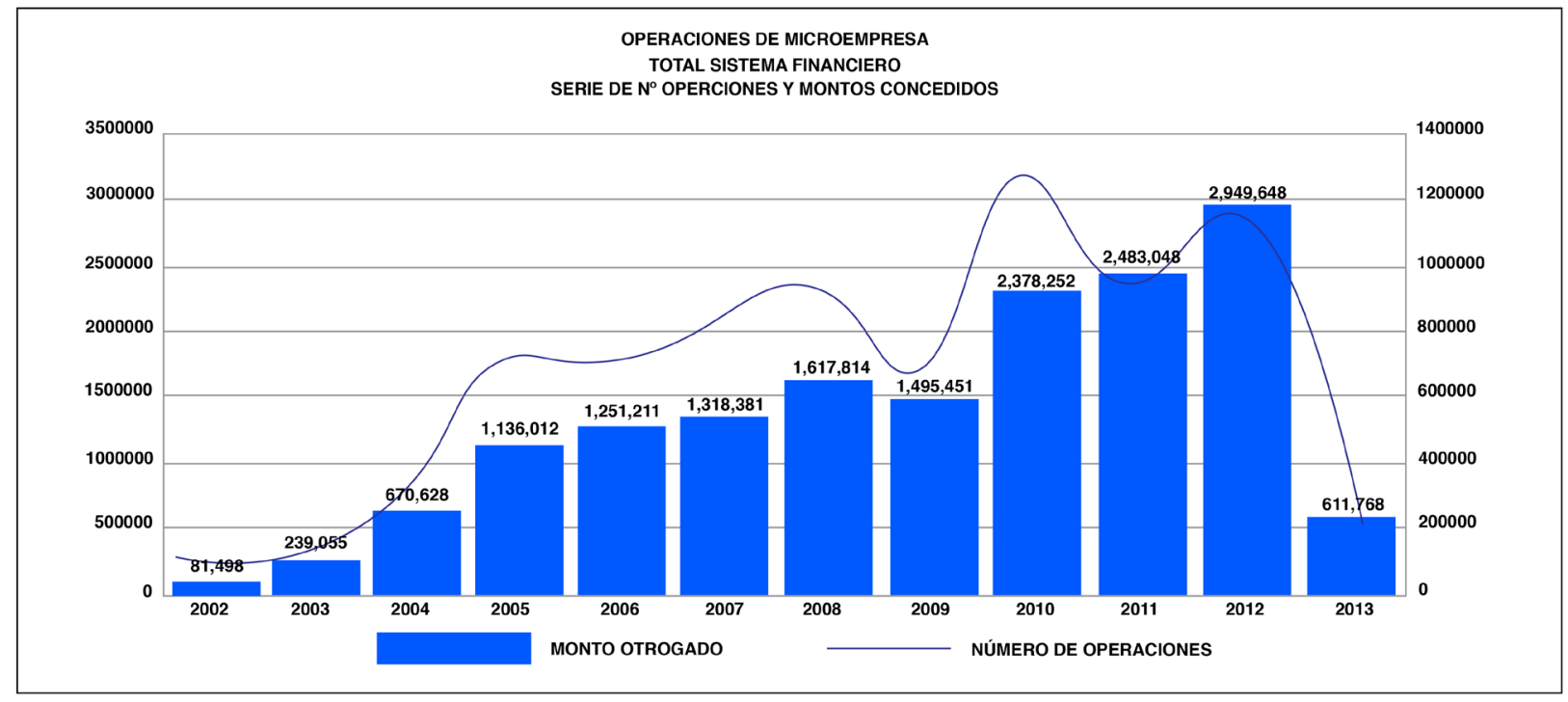

Fuente: http://www.sbs.gob.ec/practg/sbs_index (consulta, 22/08/2012) 
De manera específica al realizar el análisis a finales del año 2012, las microempresas han recurrido a préstamos en la banca privada en un $63.05 \%$, registrándose 718.832 operaciones financieras, lo cual denota que existe alta necesidad crediticia, es así que para el año en análisis se registran un total de 1'140.104 créditos cuyo valor asciende a \$2’949.648 USD. Estos datos dejan evidenciar el escaso conocimiento de los microempresarios sobre herramientas que les permitan acceder a recursos monetarios de manera inmediata, sin poner en riesgo sus recursos.

\section{Sistema Financiero Nacional}

\begin{tabular}{|l|l|l|}
\hline \multicolumn{1}{|c|}{ Tipo de entidad financiera } & \multicolumn{1}{c|}{$\mathbf{N}^{\mathbf{0}}$ Operaciones } & \multicolumn{1}{c|}{ Porcentaje } \\
\hline Bancos privados & 718,832 & 63.05 \\
\hline Cooperativas & 198,375 & 17.40 \\
\hline Mutualistas & 1,037 & 0.09 \\
\hline Sociedades financieras & 17,684 & 1.55 \\
\hline Banca pública & 204,176 & 17.91 \\
\hline Total operaciones & $\mathbf{1 , 1 4 0 , 1 0 4}$ & $\mathbf{1 0 0}$ \\
\hline
\end{tabular}

Elaborado por: Msc. Juan D. Martínez Guevara.

Fuente: http://www.sbs.gob.ec/practg/sbs_index (consulta, 22/08/2012)

Estudios realizados por la USAID, corroboran la importancia de las microempresas en la economía nacional al mencionar que éstas proporcionan trabajo para un estimado de 1.018 .135 personas cerca del $25 \%$ de la mano de obra urbana. Además, las ventas de estas representan aproximadamente $25.7 \%$ del PIB y sobre $10 \%$ de los ingresos netos totales en el país. Dato de vital importancia para el presente estudio, pero lamentablemente así como se generan nuevas empresas en estructuras familiares, estas también tienden a cerrarse en un alto porcentaje por la falta de recursos monetarios para mantener su operatividad, debido al desconocimiento de herramientas de Gerencia Financiera que les permita acceder a recursos económicos de manera inmediata y a bajo riesgo, una de ellas es la del Factoring o también llamado factoraje, que es una herramienta versátil y de fácil acceso para el microempresario, dándole la posibilidad de obtener liquidez mediante el proceso de venta de su cartera crediticia a una tercera empresa llamada factor.

Se puede concluir por tanto, que las microempresas son el potencial de la economía nacional, pero existen pocas posibilidades de que se mantengan en el mercado por la alta competitividad, y sobre todo por el desconocimiento de la gestión financiera en el uso de instrumentos que les permitan acceder a recursos monetarios de manera inmediata, se podría decir que muy pocas de ellas aplican herramientas financieras como el Factoring 
que les permite administrar sus cuentas por cobrar, y por tanto se genera una pérdida de oportunidad, lo cual las hace más vulnerables.

\section{Justificación}

La importancia de la participación de las microempresas en la economía actual, ha sido objeto de innumerables estudios estadísticos e investigaciones, pues su participación en el mercado genera nuevas fuentes de empleo, mejoran los ingresos en las familias, lo cual constituye la esencia de la estructura social. Es así como la USAID (2011) en uno de los estudios realizados menciona que "más de un tercio (33.5\%) de hogares en áreas urbanas de ingresos medios y bajos tuvo uno o más miembros adultos de la familia con una microempresa". (p.15)

El vincular el desarrollo microempresarial con herramientas financieras para la administración de cuentas por cobrar es de vital importancia, pues este tipo de negocios se manejan con créditos a corto plazo tanto para proveedores como para clientes, y debido a la falta de experticia se genera una falta de liquidez, por tanto realizar un estudio sobre el Factoring como herramienta financiera para mejorar las posibilidades de adquirir liquidez en éste tipo de empresas, se convierte en un aporte importante para este sector productivo, puesto que les es difícil obtener recursos monetarios, debido a que las instituciones financieras limitan la entrega de créditos a empresas pequeñas por los riesgos operativos y crediticios que puede enfrentar la banca, ante las posibilidades de recaudar el dinero prestado.

\section{Marco teórico}

\section{Microempresas: definición}

Según datos tomados del artículo SEMINARIO-TALLER: Mecanismos de producción de exportaciones para las MIPYMES en los países de la ALADI - CAPEIPI, en el Ecuador de acuerdo a su tamaño, las microempresas tienen las siguientes categorías:

Microempresas: emplean hasta 10 trabajadores, y su capital fijo (descontado edificios y terrenos) puede ir hasta los 20 mil dólares.

Talleres artesanales: se caracterizan por tener una labor manual no con más de 20 operarios y un capital fijo de 27 mil dólares.

En el decreto ejecutivo 107, del 14 de enero de 1993, se define a la microempresa como:

...”la unidad económica operada por personas naturales, jurídicas o de hecho formales o informales, de autoempleo o que tengan hasta 10 colaboradores y con un capital de trabajo de hasta 20.000 USD, que no incluya inmuebles y vehículos que sean herramientas de trabajo, registrados en una organización gremial microempresarial 
y que se dedican a actividades de producción, comercio o servicios, en los subsectores de alimentos, cerámico, confecciones, textil, cuero y calzado, electrónico, gráfico, químico, plástico, materiales de construcción, maderero, metalmecánica, profesionales, transporte, restaurantes, hotelería y turismo, ecológicos, cuidado de carreteras o mantenimiento vial, $y$ otras actividades afines.

Analizadas las acepciones anteriores se puede determinar que una microempresa, es un negocio en el cual operan no menos de 10 empleados, el cual es administrado por una persona o una familia, que puede constituirse como persona jurídica o natural para realizar sus actividades comerciales, de servicios o de producción.

Este tipo de negocios se caracterizan por tener estrecha relación con sus colaboradores por su reducido tamaño, se manejan en el sistema empresarial con cierta informalidad, son generadores de ingresos importantes en el desarrollo empresarial, dando un aporte significativo del PIB, dependen de la calidad de mano de obra. En el aspecto económico financiero, carecen de experticia en la gestión financiera tanto de sus recursos económicos, como de otros activos sean estos inventarios o cuentas por cobrar, enfrentan alta competitividad en el mercado, y tienen dificultades a los accesos a créditos.

\section{Factoring herramienta financiera para microempresas}

\section{Historia del Factoring}

Estudios realizados por Hillyer en su obra Four centuries of Factoring, The Quarrer, y enunciados por Sánchez Fernández en su obra sobre el Factoring, menciona que los inicios de esta actividad financiera se remontan a "Babilonia época de Hammurabi (1792-1750)", (306) además afirma que las primeras manifestaciones del factoraje aparecen en la "Cultura Neobabilónica de los Caldeos, revistiendo la condición de un comisionista, que mediante el pago de una suma de dinero, protegía a su cliente de los riesgos de operación”. (Del Vechio. p 300).

Otra de las manifestaciones del origen de este procedimiento financiero se remonta al siglo XVII. Debido a las dificultades en el cobro de las manufacturas (principalmente textiles) que Inglaterra exportaba a Estados Unidos, las empresas inglesas comenzaron a delegar la tarea de venta y cobro a empresarios norteamericanos. El desplazamiento de un continente a otro encarecía la operación comercial, a lo que se agregaba la falta de información sobre el cliente. Con el tiempo los empresarios norteamericanos comenzaron a asumir el riesgo comercial de las ventas y a realizar adelantos financieros a los exportadores ingleses.

Si bien Estados Unidos fue pionero en este negocio, la mayor parte del Factoring se realiza actualmente en Europa. Aunque la mayoría de los negocios de ésta naturaleza está concentrada en el factoraje doméstico, es decir, dentro del país, cada día va tomando más importancia el Factoring internacional o de exportación. (POBLETE, 2010) 


\section{Definición del término Factoring}

Factoring al igual que muchas palabras que se usan de manera cotidiana o técnica, proviene de un vocablo de origen latino, como lo manifiesta Sánchez Fernández, determinar que la expresión que le antecede es "farece", cuyo significado es "el que hace", es decir que es la designación a quien realiza una acción por cuenta de otro. $\mathrm{Al}$ respecto se puede decir que facere, en castellano factor es el agente comercial encargado de realizar una actividad por otra.

El término factoraje no es nuevo en el entorno financiero, este se deriva de la palabra factor, cuyo origen nace en el Derecho Romano, por su aplicación en la práctica mercantil, es así que Roca (2005), establece que:

..."el factor o persona encargada de realizar un negocio por otro, no aporta a la institución del Factoring otra cosa que los orígenes de la palabra, que acaso conserve como un producto residual de esta función de realizar algo por otro, que al fin y al cabo se encuentra tanto como en el Factos más primitivo como en el Factoring más moderno" (p.11)

Lisoprawski \& Gerscovich (1997) conceptúan básicamente al factoring como una operación empresarial de transferencia de documentos comerciales, es así que la definen como:

... "aquella operación por la cual un empresario transmite, con o sin exclusividad, los créditos que frente a terceros tiene como consecuencia de su actividad mercantil, a un factor, el cual se encargará de la gestión y contabilización de tales créditos, pudiendo asumir el riesgo de insolvencia de los deudores de los créditos cedidos, así como la movilización de tales créditos mediante el anticipo de ellos a favor de su cliente; servicios desarrollados a cambio de una prestación económica que el cliente ha de pagar (comisión, intereses) a favor de su factor. Advertimos así como característica saliente la triple finalidad del Factoring: gestión, garantía y financiación de los créditos". (págs. 15-16)

En torno a la temática han surgido definiciones financieras de varios especialistas en el área, quienes coinciden en la funcionalidad de la definición con las operaciones mercantiles que realizan las empresas, entre ellas se pueden citar a varios de ellos, siendo estos:

- Van Horne \& Wachowicz (2002), quienes conciben el factoraje como la "venta de cuentas por cobrar a una institución financiera, este procedimiento financiero se da cuando un empresa transfiere la titularidad de venderlas a un factor" (p.305)

- Para Lawrence J. Gitman (2000), el factoraje se relaciona con "la venta directa de las cuentas por cobrar de una empresa a un Factor o Institución Financiera". (p.321)

- Graham et.al (2011), mencionan que en el "entorno financiero de hoy, existen muchas oportunidades para que las empresas recurran al outsourcing" para adquirir liquidez inmediata mediante la disponibi- 
lidad de los documentos comerciales de sus cuentas por cobrar a corto plazo, conocido como factoraje a dicha acción "que implica la venta directa de las cuentas por cobrar a un tercero, haciéndole un documento". (p.739)

- Weston \& Brigan (1995), lo definen como la "la forma de financiamiento mediante la compra de las cuentas por cobrar por el factor de responsabilidad para el prestatario (vendedor). El comprador de los bienes notificado de la transferencia y hace el pago directamente al factor".

- Muldord (1980), define al Factoring como la forma tradicional de pago por "el factor a una industria o comerciante, de las facturas que ellos tienen sobre sus compradores", el autor mencionado afirma que dicho pago tiene origen en la "transferencia de los créditos", en dicha operación comercial existe la participación de la "técnica bancaria y del seguro" (p.2).

Los múltiples aportes con referencia al origen del término Factoring y su definición se establece que esta es una técnica financiera que se ejerce mediante la acción de transferir los títulos de crédito de corto plazo que forman parte de la cartera crediticia a una organización o empresa a otra denominada empresa de factoring, que se encargará de la recuperación de los mismos. Es un servicio financiero práctico, versátil y elemental que se ha generado fuera del sistema de crédito tradicional con la finalidad de brindar solución inmediata a los problemas de liquidez que pueden enfrentar las microempresas.

\section{El Factoring y las microempresas}

La acción de Factoring para las microempresas, se realiza mediante la determinación de una relación de mutuo acuerdo, cuya legalización da origen a un contrato de factoraje en el que su definición ha sido dada por varios juristas especializados en el área empresarial, así para el profesor uruguayo Carlos Eduardo López Rodríguez (2003), el Factoraje “...es el contrato por el cual una parte, denominado el factoreado se obliga a ceder lo créditos actuales o futuros que tenga sobre su clientela, y la otra parte, denominado el factor se obliga a intentar su cobranza o a adquirirlos, anticipándole a aquél, una parte del cobro como precio por la cesión a cambio de una comisión.”

Farina \& Fajre (1999) han definido al contrato Factoring como una relación jurídica:

... "en la que una de las partes, que puede denominarse empresa de factoring -factor-, adquiere todos, o tan sólo una porción o una categoría de créditos, que la otra parte -empresa o cliente factoreada- tiene frente a sus clientes. Y prescindiendo de las modalidades y servicios optativos, se lo ha considerado como un contrato financiero que se celebra entre una entidad financiera (sociedad de factoring) y una empresa (factoreada), por el cual la primera se obliga a adquirir todos los créditos que se originen a favor de la segunda, en virtud de su actividad comercial, durante un determinado plazo." (p.161). 
Se establece entonces la existencia de un contrato de Factoring cuando una microempresa instituye una relación legalmente constituida, a través de un acuerdo de negociación para la venta de su cartera crediticia a una empresa denominada factor, para que realice el cobro de la misma asumiendo los riesgos de recuperación.

Las empresas que brindan los servicios de factoraje en la actualidad, ofrecen una variedad de servicios administrativos y financieros, entre los cuales se destacan la gestión y cobro de los créditos cedidos por el cliente y aceptados en cada caso por el factor, el cual asume, en las condiciones de contrato, el riesgo de insolvencia de los deudores. Para Poblete (2010), esta "concepción tradicional (Old Line Factor), ha evolucionado incorporando al Factoring la concesión de anticipos en efectivo al cliente sobre el importe de los créditos cedidos (New Style Factor).” (p.6)

Guillermo Cabanellas de Torres (1994) en el Diccionario Enciclopédico de Derecho Usual, define el Contrato de Factoring como:

... "una operación de crédito, de origen norteamericano, que consiste en la transferencia de un crédito mercantil del titular a un factor que se encarga, contra cierta remuneración o comisión, de obtener el cobro, cuya realización se garantiza, incluso en el caso de quiebra temporal o definitiva del deudor. Constituye, pues, una comisión de cobranza garantizada."

Analizadas las conceptualizaciones dadas, el contrato de factoraje es una de las alternativas más idóneas para las microempresas que requieren de efectivo de manera inmediata para realizar sus actividades operativas, mediante esta relación legal una empresa no financiera puede ceder a una unidad de crédito o empresa no financiera puede ceder a una unidad de crédito o empresa de factoraje (factor), una o varias cuentas por cobrar provenientes de su actividad comercial para obtener efectivo de manera inmediata.

\section{Oferta de Factoring}

En la actualidad el Factoring lo realizan tanto las entidades financieras como bancos, cooperativas o entidades crediticias; como empresas privadas, cuya actividad principal es la prestación de servicios para la recaudación de cartera crediticia, a cambio de una comisión por el acto de cobranza, esta modalidad en la actualidad se ha modificado pues la empresa que realiza el Factoring, compra los documentos comerciales y realiza el proceso de cobro asumiendo los riesgos de dicho procedimiento, es así que en el mercado existen muy pocas ofertas de factoring dadas por empresas privadas, entre las de mayor posicionamiento de mercado se encuentra: Pro-factura, Logros Factoring, Gestomatic Soluciones Financieras.

En los últimos años las instituciones financieras no le han dado la verdadera importancia al Factoring como servicio financiero, de allí que muy pocos bancos que lo ofertan, entre ellos se puede mencionar al Banco Bolivariano y al Banco Pichincha. 
Es importante señalar y de manera significativa me permito nombrar a la Corporación Financiera Nacional que es una institución financiera pública, cuya misión consiste en canalizar los productos financieros y no financieros alineados al Plan Nacional del Buen Vivir para servir a los sectores productivos del país, la cual en la actualidad se encuentra ofertando los servicios de factoraje bajo las siguientes características:

\begin{tabular}{|c|c|c|}
\hline Empresas privadas & Tipos de servicios ofertados & Caracteríasticas del contrato \\
\hline \multirow{2}{*}{$\begin{array}{c}\text { CNF } \\
\text { Corporación Financiera Nacional }\end{array}$} & $\begin{array}{l}\text { Factoring Local } \\
\text { Capital de trabajo generado a través de la } \\
\text { compra de facturas por cobrar de las ven- } \\
\text { tas efectuadas en territorio nacional. } \\
\text { La tasa de interés anual se encuentra en el } \\
\text { rango de } 8.5 \% \text { y } 9.75 \%\end{array}$ & \multirow{2}{*}{$\begin{array}{l}\text { Modalidad } \\
\text { Línea de crédito de un año plazo. CFN } \\
\text { financiará facturas cuyo vencimiento no } \\
\text { supere los } 90 \text { días desde la fecha de su } \\
\text { emisión. Se excluyen facturas venciadas. } \\
\text { Garantías } \\
\text { Todas las permitidas según la Superinten- } \\
\text { dencia de Bancos, previa inspección y eva- } \\
\text { luación de la CFN. } \\
\text { La garantía debe tener una cobertura míni- } \\
\text { ma del } 100 \% \text { de cada operación. }\end{array}$} \\
\hline & $\begin{array}{l}\text { Factoring Internacional } \\
\text { Capital de trabajo generado a través de la } \\
\text { copra de facturas por cobrar de las ventas } \\
\text { efectuadas en el mercado internacional. } \\
\text { La tasa de interés anual se encuentra en el } \\
\text { rango de } 7.5 \% \text { y } 8.75 \%\end{array}$ & \\
\hline
\end{tabular}

Elaborado por: Msc. Juan D. Martínez Guevara.

Fuente: http://www.cfn.fin.ec/index.php?option=com (consulta, 24/08/2012)

\section{Factoring herramienta financiera para microempresas}

En todo caso de Factoring intervienen varios actores, siendo estos:

Emisor o cliente: es la persona natural o jurídica (empresa), quien vende o cede los derechos sobre sus cuentas por cobrar en la forma total o parcial a un tercero con la finalidad de obtener liquidez inmediata y poder cubrir con sus obligaciones o requerimientos.

Factor o factoring: es la empresa que ofrece sus servicios de administración de las cuentas por cobrar del emisor, o realiza la compra de los derechos económicos de 1 cartera de sus clientes. Según Mulford (1980), determina que para poder ofrecer los servicios de factoraje, la empresa de Factoring "dispone de un departamento de información comercial lo suficientemente grande y eficiente". (p. 48) 
Pagador: es el titular de la deuda, quien adquiere el factor. El pagador es quien documenta al cliente del Factoring por haber recibido productos o servicios.

\section{Instrumentos del Factoring}

$\mathrm{Al}$ establecerse un contrato de factoring las microempresas pueden optar el servicio de negociación de cuenta por cobrar, en esta modalidad la empresa cede sus cuentas por cobrar vigentes como facturas, pagarés, letras

Gráfico $\mathrm{N}^{\circ}$ 1: Formato de factura autorizada por el SRI.

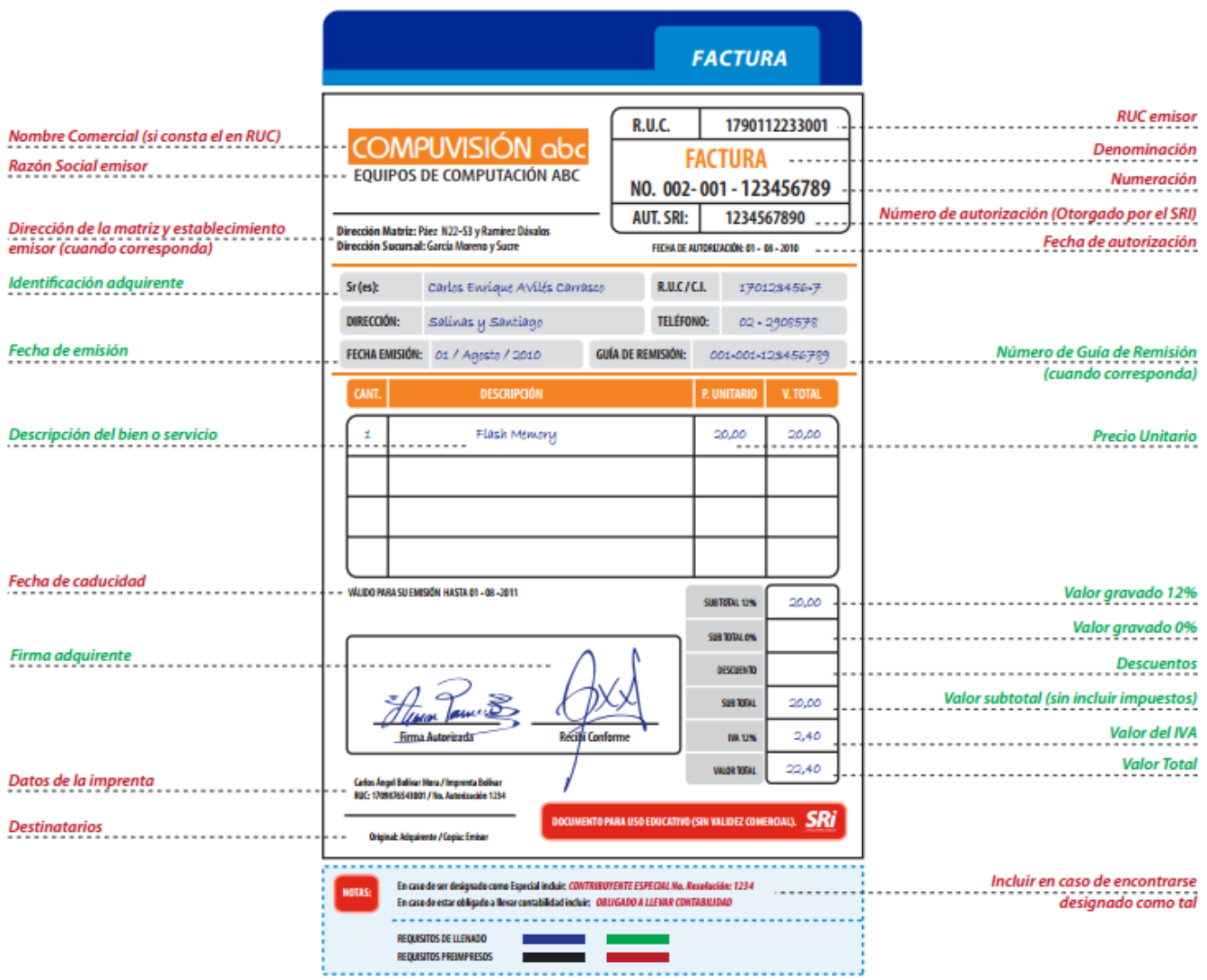

Fuente: Servicio de Rentas Internas, pág web. www.sri.gob.ec 
de cambio, entre otros a la empresa de factoring, para así contar con los recursos anticipadamente y tener el flujo de efectivo necesario para la realización de sus operaciones y que no se detengan por la falta de efectivo.

Los documentos que legalmente se pueden negociar en un proceso de factoraje son las facturas, para el efecto la factura debe cumplir con determinados requerimientos básicos establecidos por la Ley mediante el Servicio de Rentas Internas [SRI], entidad que respalda las transacciones efectuadas por los contribuyentes en la transferencia de bienes, a continuación se puede apreciar una factura que cumple con lo estipulado en la Ley.

\section{Ventajas y desventajas para las microempresas en los procesos de Factoring}

\section{a. Ventajas para las microempresas en los procesos de Factoring}

Entre las ventajas que pueden tener las microempresas al optar por el proceso de Factoring para la obtención de recursos monetarios en el corto plazo, se mencionan:

- Obtener liquidez de manera inmediata sin poner en riesgo sus bienes y sin generar pasivos.

- Reducir su cartera crediticia.

- El contrato de Factoring no presenta para el cliente riesgos crediticios.

- Incrementar la posibilidad de recursos a medida que aumentan las ventas.

- Ampliación de los términos de venta.

- Reduce la carga y costos operativos.

- Obtener flujo de caja sin necesidad de anticipo por parte de sus clientes.

- Reservar las líneas de crédito bancario para proyectos a largo plazo.

- Permite planificar mejor su flujo de caja.

- La compañía de Factoring se encarga de la gestión de cobranza.

- Convierte sus ventas a plazo en ventas al contado.

- Mejora sus indicadores financieros.

\section{b. Desventajas para las microempresas en los procesos de Factoring}

Entre las desventajas que pueden tener las microempresas al optar por el proceso de factoring para la obtención de recursos monetarios en el corto plazo, se mencionan:

- Altos costos financieros que debe asumir la microempresa.

- Desgaste de su imagen empresarial ante el mercado en el que se desenvuelve al denotar su falta de liquidez.

- Análisis de su cartera de cuentas por cobrar, con la posibilidad de no ser aceptada por la empresa de factoraje. 


\section{Conclusiones}

El presente documento ha permitido analizar la relación de las microempresas con la utilidad que pueden brindar las herramientas financieras como es el factoring, pudiéndose concluir que la aplicación de esta herramienta es una alternativa financiera segura y sólida, que apoya al crecimiento económico en las microempresas.

Este medio de financiamiento es una forma descomplicada de acceder a recursos monetarios a corto plazo, lo que le permite a las microempresas obtener liquidez, elevar su nivel de competitividad, reinvertir y por ende mejorar su posición en el mercado. A pesar de ser una alternativa de alto costo debido a que la empresa de factoring o factor cobra altos rubros, esta es la que asume los riesgos de cobro de los documentos comerciales transferidos por sus clientes. 


\section{Bibliografía}

Cabanellas de Torres, Guillermo: Diccionario Enciclopédico de Derecho Usual. Tomo IV. Editorial Hiliasta. 23․ Buenos Aires, Argentina. 1994

Corporación Financiera Nacional. http://www.cfn.fin.ec/index.php

Del Vechio, G. Filosofía del Derecho. Editorial Casa Bosh. Barcelona, España. 1980.

Farina, Juan M. \& Fajre, José Benito. Contratos Financieros. Factoring, en: Contratos Especiales en el Siglo XXI. (Roberto López Cabana, coordinador). Abeledo-Perrot editores. Buenos Aires, Argentina. 1999.

Lawrence J. Gitman. Fundamentos de Administración Financiera. $8^{\circ}$ Edición. Editorial Mc. graw Hill. México, 2000.

Graham, Jhon R., Smart, Scott B. Megginson, William L. Finanzas Corporativas. $3^{\circ}$ edición. Editorial CENGACE learning. México. 2011.

Hillyer. Four centuries of factoring. The Quarrel Journal of Economics. Vol. LIII. No 2. febrero 1939.

Lisoprawski, Silvio V. Y Gerscovich, Carlos G. Factoring. Análisis integral del negocio, aspectos legales, comerciales y operativos, financiamiento de las PYMES modelos de contrato. Depalma. $1^{\circ}$ Edición. Editorial Lexis-Nexis. Buenos Aires, Argentina. 1997.

López Rodríguez, Carlos Eduardo. Factoraje o Factoring. www.derechocomercial.edu.uy/Bol11Factoring.htm . Montevideo, Uruguay. 2003.

Mulford F. Algunas anotaciones sobre el contrato de factoring. Pontificia Universidad Javeriana. Bogotá, Colombia. 1980.

Poblete, Daniela. Mercado de Capitales y productos financieros. Chile, 2010.

Roca G. El contrato de Factoring y su regulación por el Derecho Español. Editorial de Derecho Reunidas. Barcelona, España. 1976.

Sánchez Fernández Valderrama, José Luis. El factoring garantía de financiamiento y servicios. Asociación para el progreso de la dirección. Madrid, España. 1972.

Servicio de Rentas Internas. www.sri.gob.ec. Quito, Ecuador

Van Horne, James C., Wachowicz, John M. Jr. Fundamentos de la Administración Financiera. $11^{\circ}$ Edición. Editorial Pearson Prentice Hall. México. 2002.

Weston, Fred J. \& Brighan, Eugene F. Fundamentos de Administración Financiera. 10 edición. Mc Graw Hill, México. 1995. 
